\title{
Keratinocytic Cancers - Ambulatory Surgical Approach: Case Series
}

\author{
Teodor Angelov ${ }^{1}$, Ana Bitolska², Georgi Tchernev ${ }^{2 *}$ \\ ${ }^{1}$ Student, state trainee, Faculty of Medicine, Medical University of Sofia, Bulgaria \\ ${ }^{2}$ Onkoderma-Clinic for Dermatology, Venereology and Dermatologic Surgery, General Skobelev, Sofia, Bulgaria
}

Received: August 24, 2020; Accepted: August 27, 2020; Published: August 29, 2020

*Corresponding author: Professor Georgi Tchernev, PhD, Onkoderma-Clinic for Dermatology, Venereology and Dermatologic Surgery, Sofia, Bulgaria, Tel. No:00359885588424; E-mail: georgi_tchernev@yahoo.de

\begin{abstract}
The Keratinocytic cancer is the most common form of skin cancer and the most common cancer in humans. Predisposing risk factors include ultraviolet radiation, genetic predisposition, chronic immune suppression, smoking, which also determines the risk groups - middle and old age, light skin phenotype, outdoor work and frequent sunburns. The origin of the epidermal cell type determines the clinical division of keratinocytic cancer into basal cell carcinoma (BCC) and squamous cell carcinoma (SCC). Clinically, keratinocytic cancer is presented as a solitary, sometimes destructive, growing-sized lesion. The most lesions are characterized by a low degree of malignancy. Neglecting them by both the patient and medical professionals leads to their growth and metastasis, as SCC has a higher potential for metastasis. The main place in the treatment of keratinocytic cancer is the surgical method, and the most common in clinical practice is the so called elliptical excision. The gold standard in hardto-reach places is the Mohs micrographic operation. In this publication we present eleven clinical cases of patients with keratinocytic cancers in different topographic regions of the human body. Patients were treated surgically by elliptical excision and complete removal of tumor formations in accordance with the recommended fields of surgical safety. The defects were closed with single skin sutures and the sutures were removed on the 14th postoperative day. No complications were observed in the postoperative period.
\end{abstract}

Keywords: Keratinocytic Cancer; Basal Cell Carcinoma; Squamous Cell Carcinoma; Elliptical Excision; Dermatosurgery

\section{Introduction}

Keratinocytic cancer is the most common form of skin cancer and the most common cancer in humans [1]. Predisposing risk factors include ultraviolet radiation, genetic predisposition, chronic immune suppression, smoking, which also determines the risk groups - middle and old age, light skin phenotype, outdoor work and frequent sunburns [2]. It can also be found in children and people with a dark skin phenotype [2].

Keratinocytic cancer is a malignant neoplasm formed by the building cells of the epidermis - according to the histological type of superficial keratinocytes, basal cells or spinous cells [3]. Their origin determines their clinical division into basal cell carcinoma (BCC) and squamous cell carcinoma (SCC). Intraepidermal (in situ) squamous cell carcinoma, Morbus Bowen and actinic keratosis, described as precursors of SCC, are also defined as separate nosological units [3]. Accurate diagnosis and classification is important because of their effect on prognosis and treatment regimen and follow-up [1].

We present eleven clinical cases of patients with small keratinocytic cancers in different topographic regions of the body.

\section{Description of Clinical Cases}

The first patient is 72 years old and is in good general condition [Figure 1a-1e]. Anamnestic reports the appearance of a formation in the left facial area 6 months ago. His complaints include itching, mild serous secretion, and soreness. There were no data on concomitant diseases, medications and allergies. The performed clinical examination revealed a lesion, suspicious for small squamous cell carcinoma, and basocellular carcinoma and keratoacanthoma were considered in the differential diagnostic aspect. Instrumental examinations (abdominal ultrasound and lung radiography) as well as paraclinical examinations are without pathological abnormalities. Screening tests rule out metastases. The tumor formation was surgically removed by elliptical excision, and subsequent histological examination of the operative material showed clean resection lines. On the 14th postoperative day, the sutures were removed, with a good postoperative cosmetic result, with no evidence of complications in the postoperative period.

The second patient was 61 years old and was also in good general condition [Figure 2a-2d]. Anamnestic reports the appearance of a lesion in the area of the left scapula (regio scapularis sinistra) 1-2 years ago. His complaints include redness with itching, discomfort and a slight burning sensation. There are no data on concomitant diseases, medications and allergies. During the clinical examination, Morbus Bowen or 

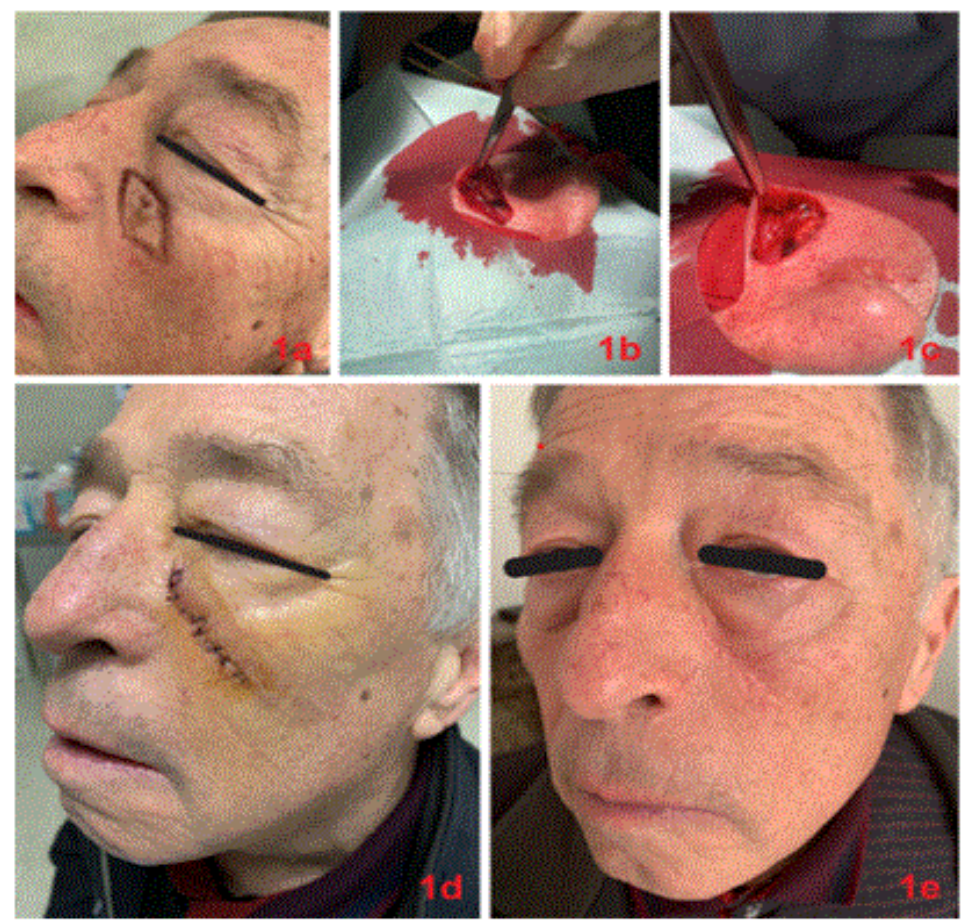

Figure 1: a: Preoperative view of small squamous cell carcinoma in the left facial region (regio facialis sinistra) in a 72-year-old patient. b/c: Intraoperative view of the resected tumor formation. d: Postoperative view of the closed operative wound with single skin sutures. e: Excellent postoperative results, 2 months after operative intervention.
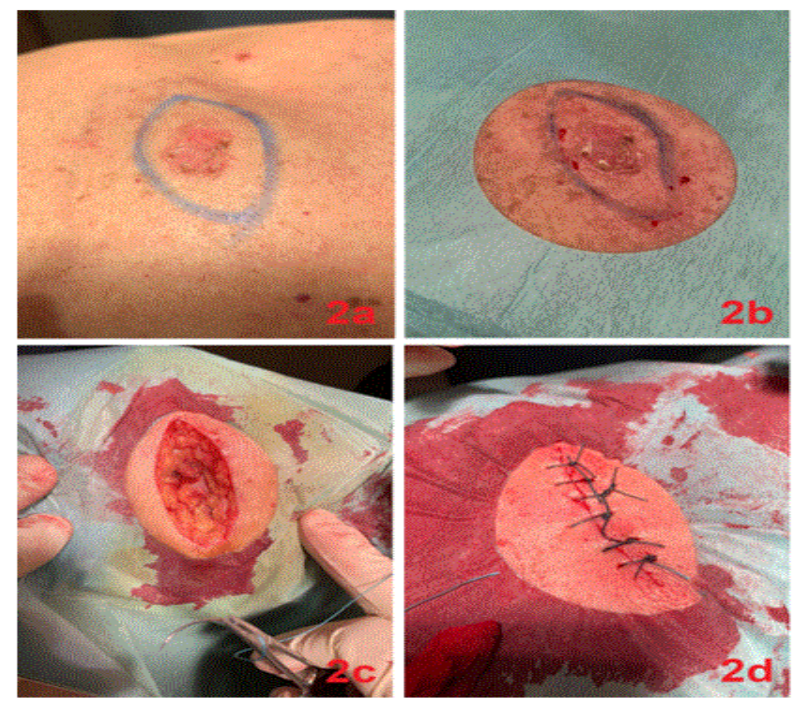

Figure 2: a/b - Preoperative view of the basal cell carcinoma in the left scapula (regio scapularis sinistra) in a 61-year-old patient. c: Intraoperative view of the resected tumor formation. d: Postoperative view of the closed operative wound with single skin sutures.

possible superficial BCC were uspected clinically. Instrumental examinations (abdominal ultrasound and lung radiography) as well as paraclinical examinations are without pathological abnormalities. Screening tests rule out metastases. The tumor formation was surgically removed by elliptical excision, and subsequent histological examination of the operative material showed another nosological unit - superficial basal cell carcinoma, and clean resection margins. On the 14th postoperative day, the sutures were removed, with a good postoperative cosmetic result, with no evidence of complications in the postoperative period.

The third patient is 76 years old and is in good general condition [Figure 3a-3d]. Anamnestic reports the appearance of a round lesion with central ulceration, 2 months ago, in the area of the left face (regio facialis sinistra). The lesion is painful, with serous to purulent secretions. The lesion is painful, with serous to purulent secretions. Clinical examination revealed keratoacanthoma, with basal cell and squamous cell carcinomas in the possible differential diagnosis. Instrumental examinations (abdominal ultrasound and lung radiography) as well as paraclinical examinations are without pathological changes. Screening tests rule out metastases. The tumor formation was surgically removed by elliptical excision, and subsequent histological verification of the operative material showed clean resection margins. On the 14th postoperative day, the sutures were removed, with a good postoperative cosmetic result, with no evidence of complications in the postoperative period.

The fourth patient is 74 years old and presented with cytologically proven squamous cell carcinoma of the scalp (left parietal, regio parietalis sinistra) and periocular high-risk basal cell carcinoma on the right (regio ocularis dextra) [Figure $4 \mathrm{a}-4 \mathrm{~d}]$. When they were diagnosed, the patient refused to be operated on and was prescribed radiation therapy. Shortly after 

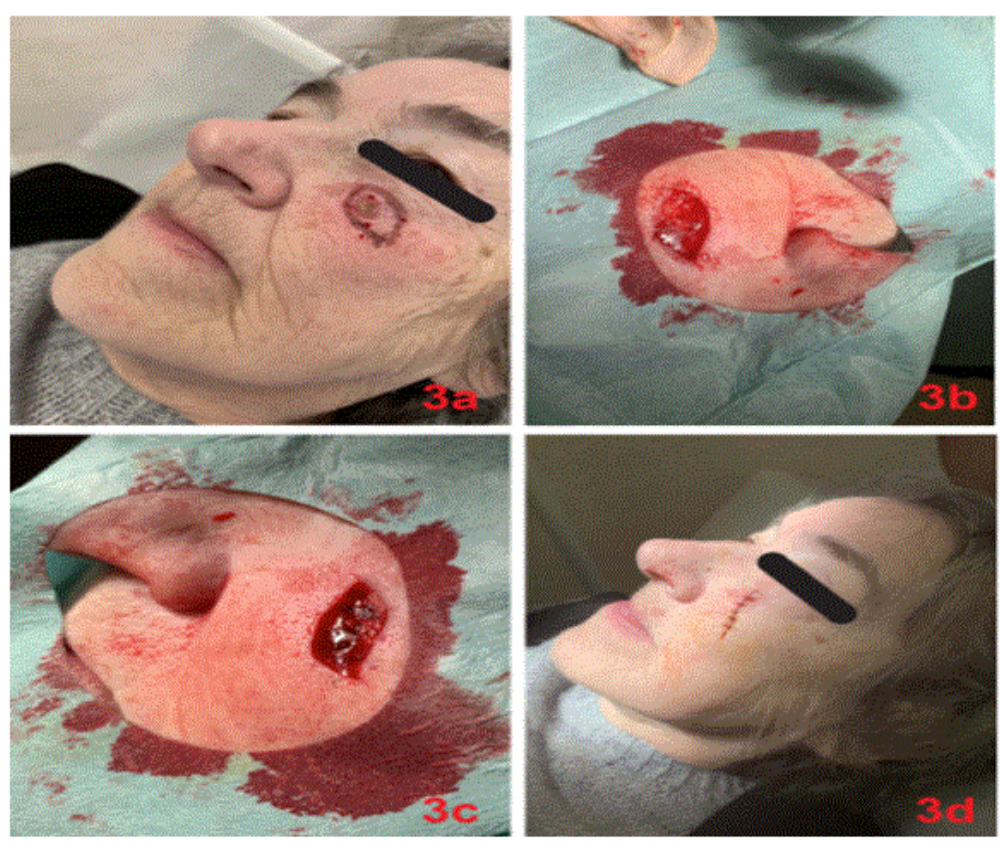

Figure 3: a: Preoperative view of keratoakanthoma like lesion in the left facial region (regio facialis sinistra) in a 76-year-old patient. b/c: Intraoperative view of the resected tumor formation. d: Postoperative view of the closed operative wound with single skin sutures. Histology has shown small SCC.
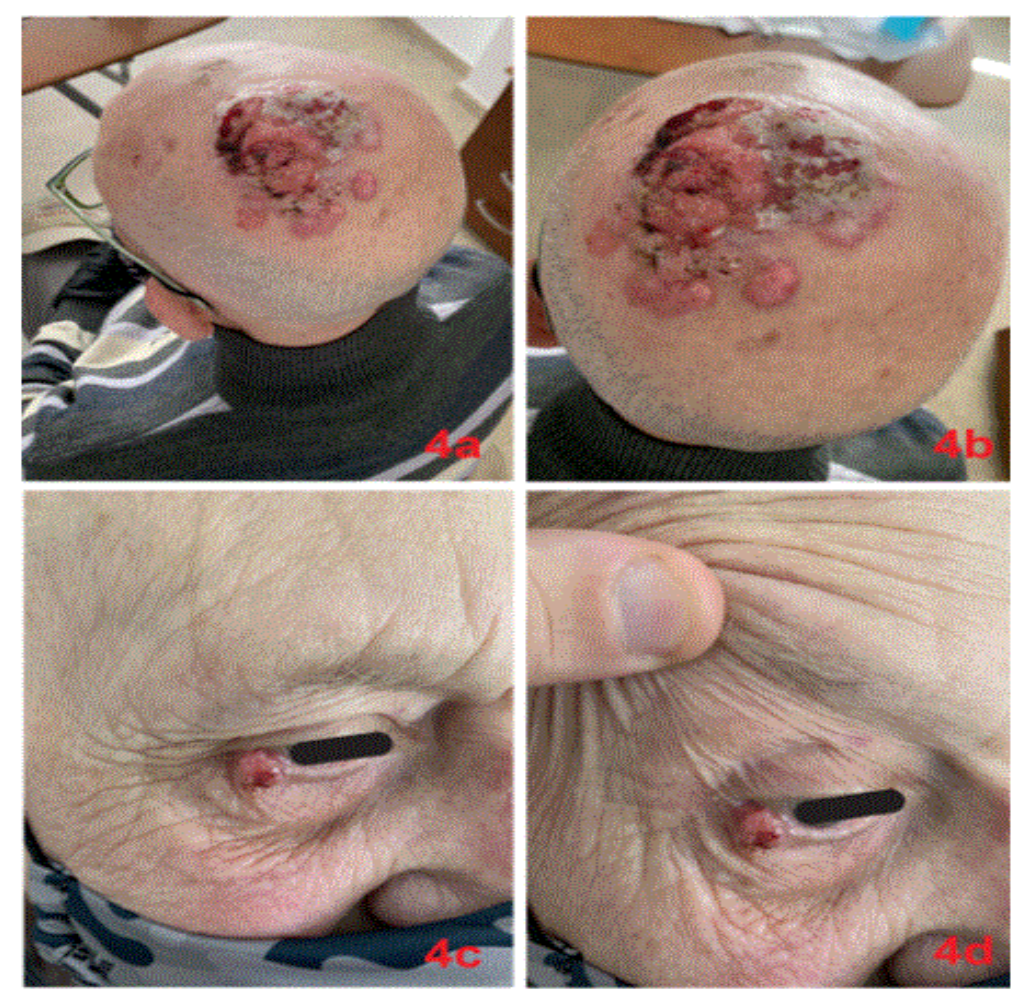

Figure 4: a / b: View of cytologically proven squamous cell carcinoma in the scalp (left parietal, regio parietalis sinistra) in a 74-year-old patient. c/d: View of periocular high-risk basal cell carcinoma on the right (regio ocularis dextra) in the same patient.

the examination, the patient suffered a trauma with a fracture of the hip joint and did not undergo radiation therapy. Within three months of diagnosis, the tumor formation in the scalp area increased significantly in size. The patient has a number 

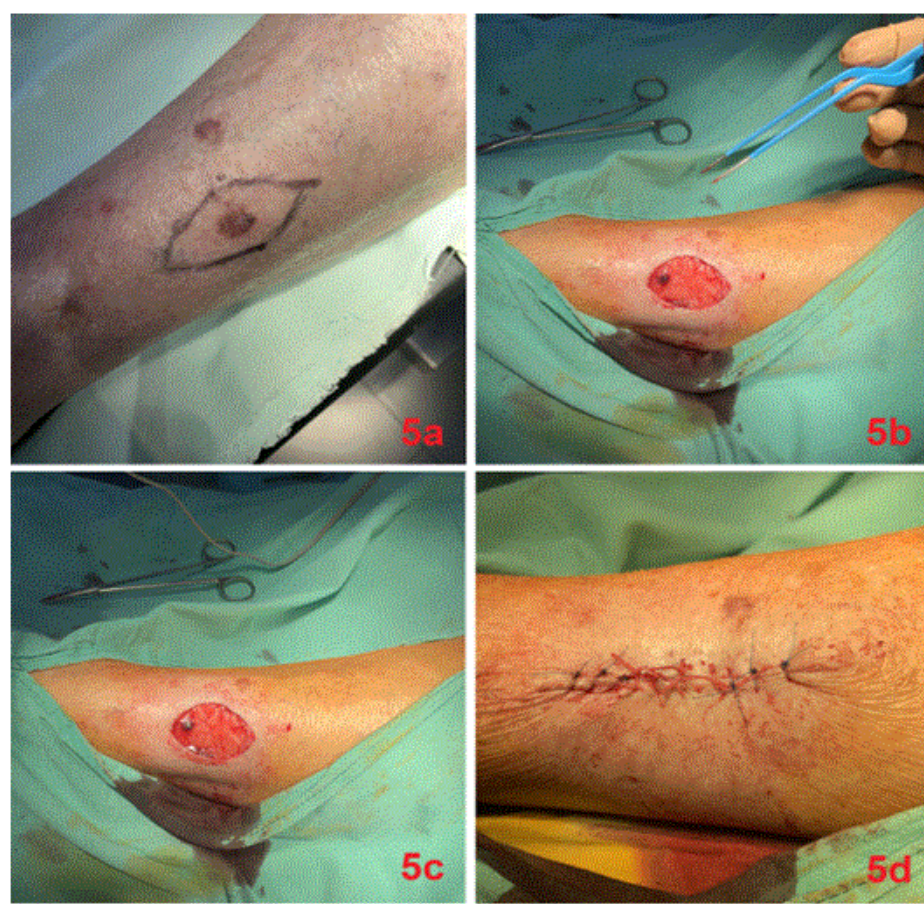

Figure 5: a: Preoperative view of two pigmented basal cell carcinomas in the left lower limb (regio cruris sinistra) in a 68-year-old patient. b/c: Intraoperative view of the resection of a tumor formation. d: Postoperative view of the closed operative wound with single skin sutures.
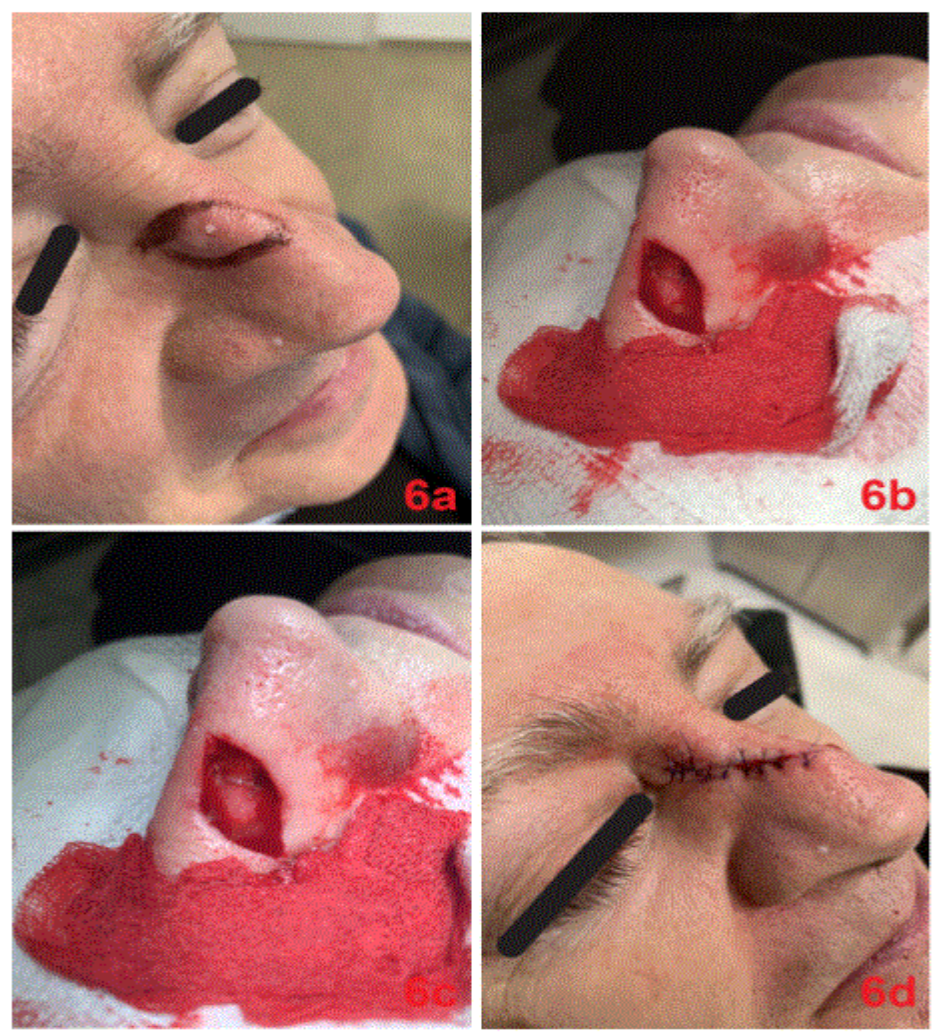

Figure 6: a: Preoperative view of initial squamous cell carcinoma of the nose (regio nasalis) in a 69-year-old patient. b/c: Intraoperative view of the resected tumor formation. d: Postoperative view of the closed operative wound with single skin sutures. 

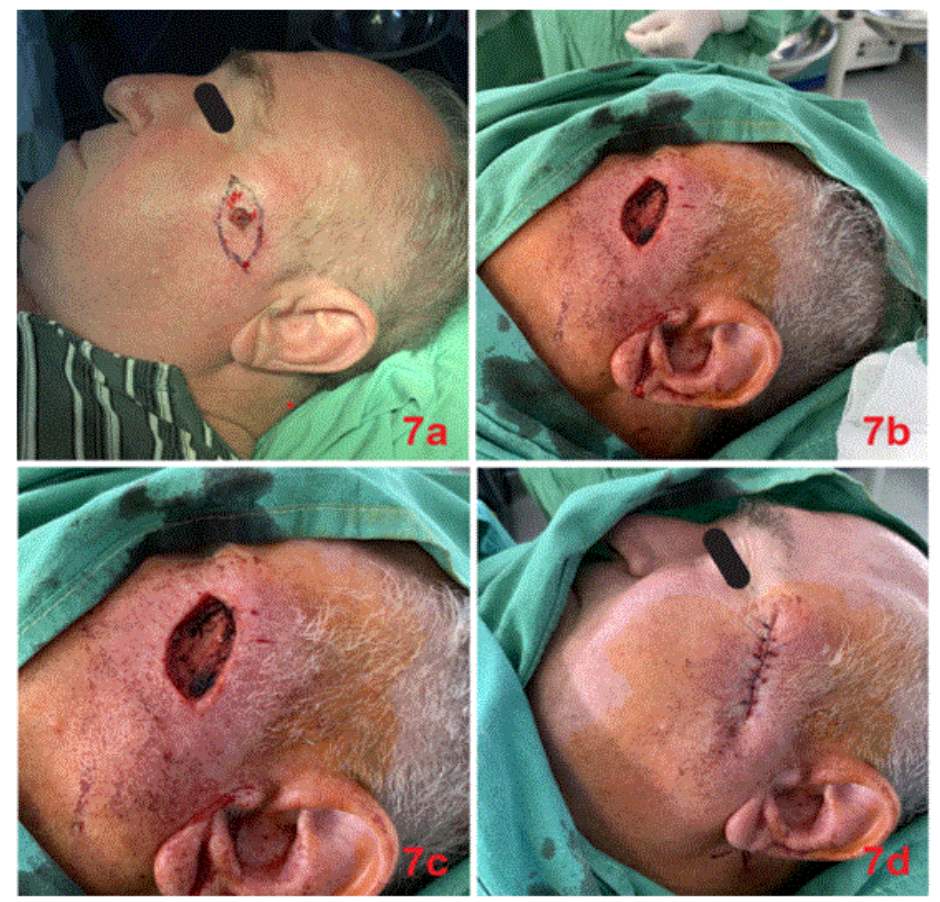

Figure 7: a: Preoperative view of a small ulcerative basal cell carcinoma in the left facial region (regio facialis sinistra) in a 72-year-old patient. b/c: Intraoperative view of the resected tumor formation. $\mathrm{d}$ : Postoperative view of the closed operative wound with single skin sutures.

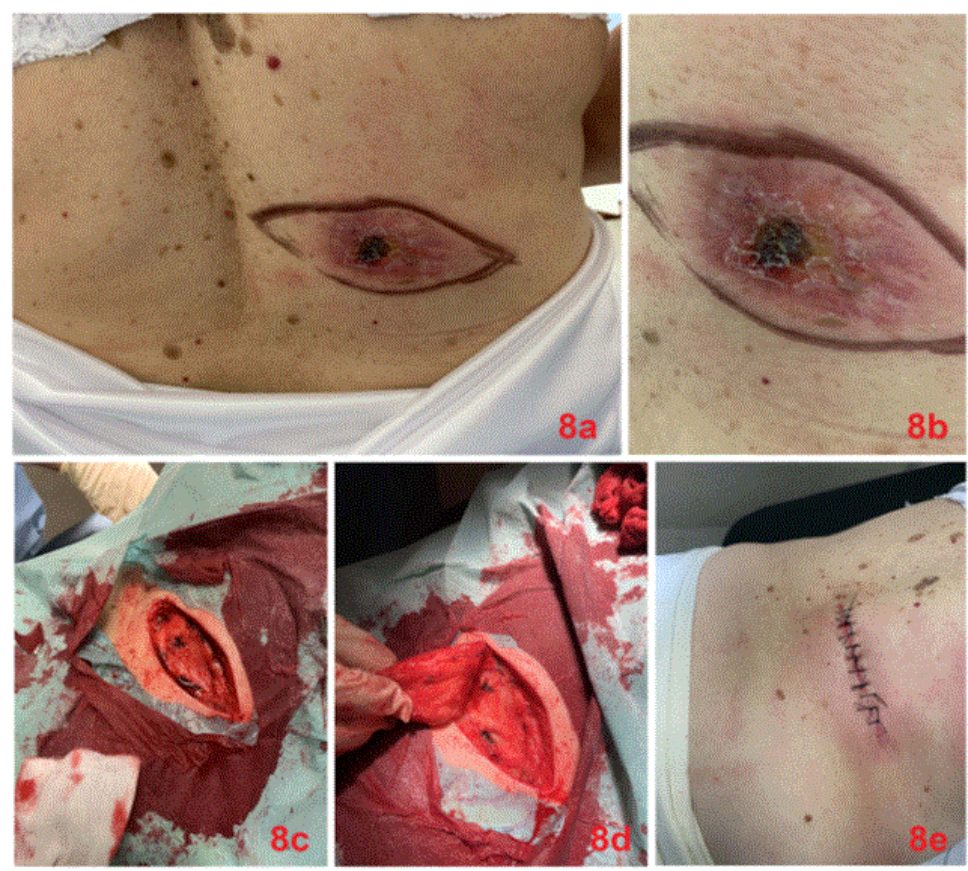

Figure 8: a/b: Preoperative view of a lesion in the back (regio lumbalis) in a 76-year-old patient. c/d: Intraoperative view of the resected tumor formation. e: Postoperative view of the closed operative wound with single skin sutures.

of concomitant diseases: chronic lymphogenic leukemia II clinical stage of Paradise with 3 courses of chemotherapy, prostate cancer for which he underwent radiotherapy, chronic HBV infection for which he conducts therapy with Lamivudine, ischemic heart disease with paroxysmal fibrillation, history of pulmonary thromboembolism with infarction-pneumonia, history of nonactive pulmonal tuberculosis, bronchiectasis and ankylosing spondylitis.. Laboratory tests show anemic syndrome. Instrumental research responds to comorbidities. 
The fifth patient is 68years old and is in good general condition [Figure 5a-5d]. Anamnestic reports of new lesions in the area of the left lower leg (regio cruris sinistra), accompanied by increased sensitivity and slight bleeding when touched and rubbed by the pants. There are no data on concomitant diseases, medications and allergies. Clinical examination revealed pigmented basal cell carcinoma, melanoma and squamous cell carcinoma were considered in the differential diagnostic plan. Instrumental examinations (abdominal ultrasound and lung radiography) as well as paraclinical examinations are without pathological abnormalities. Screening tests rule out metastases. The tumor formation was surgically removed by elliptical excision, and subsequent histological examination of the operative material showed clean resection lines. On the 14 th postoperative day, the sutures were removed, with a good postoperative cosmetic result, with no evidence of complications in the postoperative period. A second operation was planned for the adjacent lesion, which has a similar clinical morphology. The patient did not appear for the second intervention.

The sixth patient is 69 years old and is in good general condition [Figure 6a-6d]. Anamnesis reported the appearance of a lesion in the nasal region (regio nasalis) 6 months ago, during which time the lesion increased in size and was accompanied by itching, mild serous secretion and pain on touch. There are no data on concomitant diseases, medications and allergies. The clinical examination revealed an initial squamous cell carcinoma, and basocellular carcinoma was considered in a differential diagnostic aspect. The patient reported frequent sun exposure in the past and over the years, as well as painful burns as a child.Instrumental examinations (abdominal ultrasound and lung radiography) as well as paraclinical examinations are without pathological abnormalities. Screening tests rule out metastases The tumor formation was surgically removed by elliptical excision, and subsequent histological examination of the operative material showed clean resection lines On the 14th postoperative day, the sutures were removed, with a good postoperative cosmetic result, with no evidence of complications in the postoperative period.

The seventh patient is 72 years old and is in good general condition [Figure $7 \mathrm{a}-7 \mathrm{~d}$ ]. Anamnestic reports the appearance of a formation in the area of the face on the left (regio facialis sinistra) with a period of 1 year, which progressively increases in size (from the head of a warmer to over a bean in recent months). The lesion is accompanied by complaints including intermittent burning, bleeding and crusting, with no healing. There are no data on concomitant diseases, medications and allergies. The clinical examination revealed a small ulcerative basal cell carcinoma, and in the differential diagnostic aspect it was considered a squamous cell carcinoma. Instrumental examinations (abdominal ultrasound and lung radiography) as well as paraclinical examinations are without pathological abnormalities. Screening tests rule out metastases. The tumor formation was surgically removed by elliptical excision, and subsequent histological examination of the operative material showed clean resection lines. On the 14th postoperative day, the sutures were removed, with a good postoperative cosmetic result, with no evidence of complications in the postoperative period.

The eighth patient is 76 years old with histologically proven basal cell carcinoma in the back (regio lumbalis) [Figure 8a-8e]. Two two-month courses of treatment with imiquimod 5\% were performed (three times a week - Monday / Wednesday / Friday scheme). Admitted due to suspicion of ineffectiveness of therapy. The lesion was surgically removed by elliptical excision, and subsequent histological examination of the operative material showed clear resection lines and no evidence of basal cell carcinoma - biopsy data indicate fibrous tissue, inflammatory infiltrate and scarring in the area of the biopsy. These results show that in this case the clinical picture does not correspond to the histological one, as well as that the conducted therapeutic courses with imiquimod 5\% have led to clinical improvement, roven also histologically as mentioned.

The ninth patient is 43 years old [Figure 9a-9d]. Anamnestic reports the appearance of a formation in the area of the head, temporally on the right (regio temporalis dextra) 12 years ago, accompanied by subjective complaints such as discomfort, bleeding when cutting, burning when bathing and sometimes at rest. It is reported that in the last 2 months the lesion has increased in size. On clinical examination, the data showed seborrheic keratosis and a wart that developed at a later stage within the limits of keratosis. Collision tumor, keratoacanthoma and squamous cell carcinoma were considered in the differential diagnostic plan. The tumor formation was surgically removed by elliptical excision, and subsequent histological examination of the operative material showed clean resection lines. On the 14 th postoperative day, the sutures were removed, with a good postoperative cosmetic result, with no evidence of complications in the postoperative period.

The tenth patient is 45 years old and is in good general condition [Figure 10a-10d]. His complaints include discomfort in the area of the auricle (regio auricularis sinistra), burning and a small unhealed wound. Anamnestic reports frequent sunburn in childhood. There are no data on concomitant diseases, medications and allergies. Clinical studies indicate a small squamous cell carcinoma in the ear area. The tumor formation was removed by triangular excision under local anesthesia. On the 14 th postoperative day, the sutures were removed, with a good postoperative cosmetic result, with no evidence of complications in the postoperative period.

The eleventh patient is 36 years old and is in good general condition [Figure 11a-11c]. Anamnestic reports the appearance of two lesions in the facial area bilaterally (regio facialis dextra et sinistra) with a duration of 2-3 years, accompanied by burning, discomfort, mild serous secretion and pain. There are no data on concomitant diseases, medications and allergies. Clinical examination revealed basal cell carcinoma for both formations, and in the differential diagnostic aspect, squamous cell carcinoma was also considered. Instrumental examinations (abdominal ultrasound and lung radiography) as well as paraclinical examinations are without pathological changes. Screening tests 

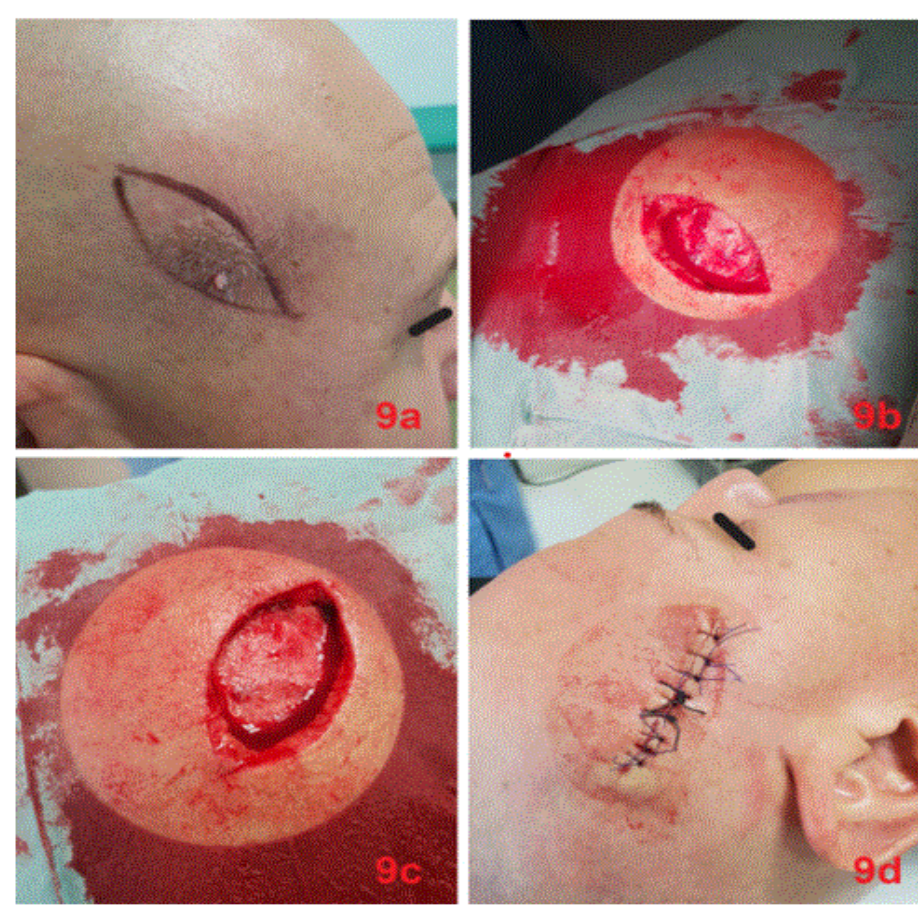

Figure 9: a: Preoperative view of seborrheic keratosis with superimposed wart on the head, temporal right (regio temporalis dextra) in a 43-yearold patient. b/c: Intraoperative view of the resected tumor formation. d: Postoperative view of the closed operative wound with single skin sutures.

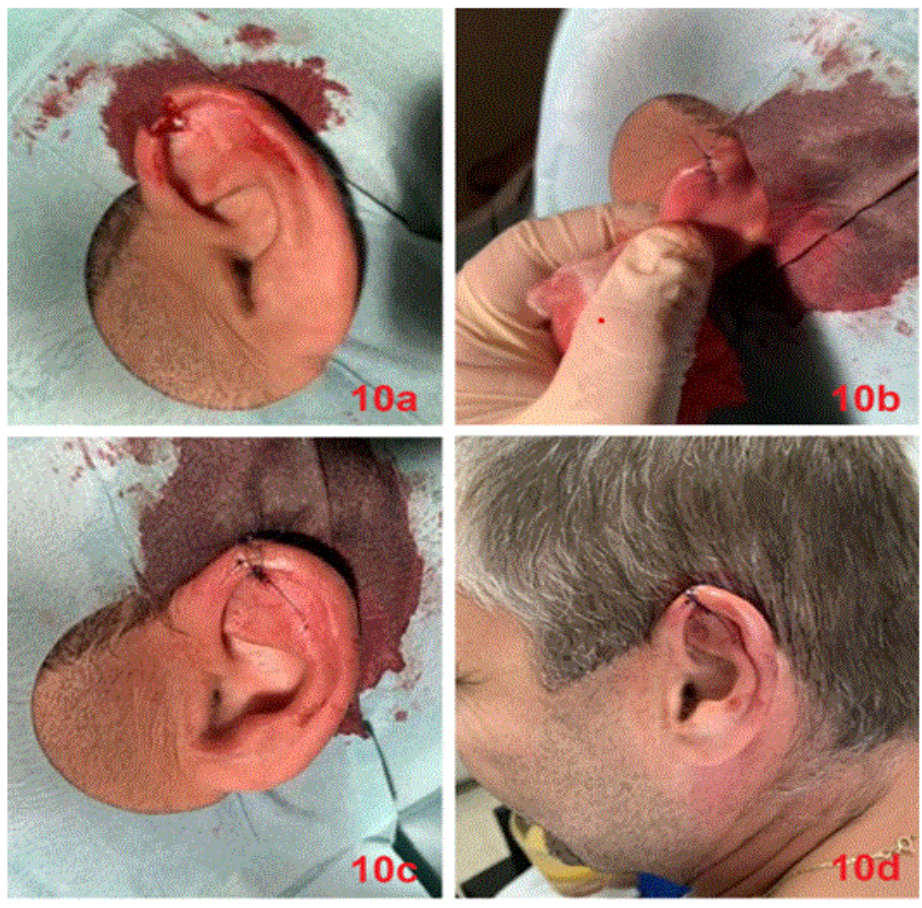

Figure 10: a: Intraoperative view of small squamous cell carcinoma in the area of the auricle (regio auricularis sinistra) in a 45-year-old patient. b-d: Postoperative view of the closed operative wound with single skin sutures. 

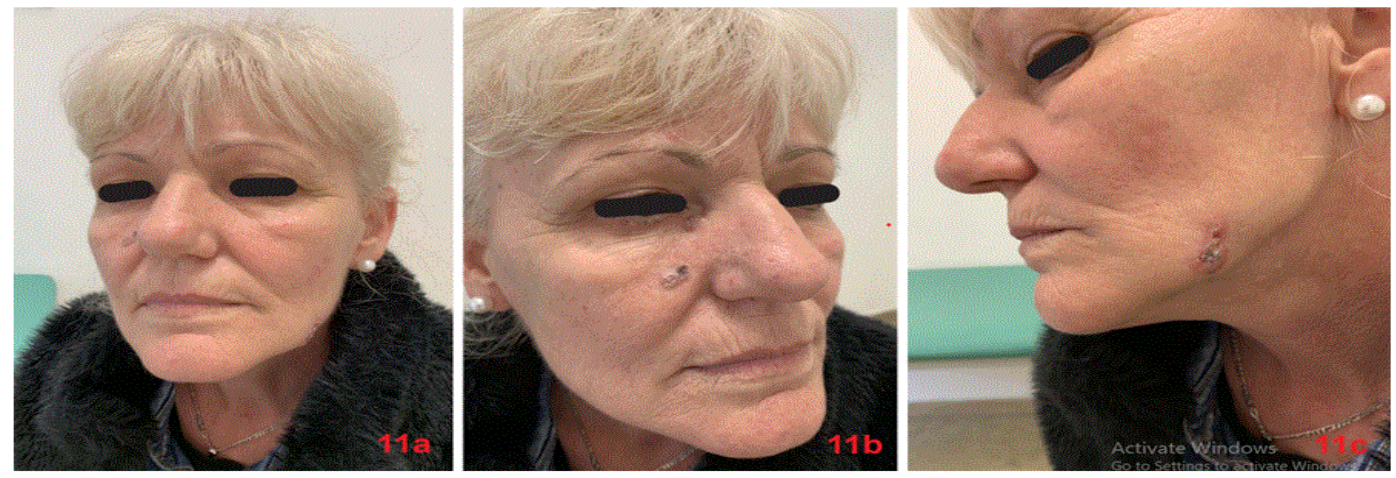

Figure 11a-11c: View of two basal cell carcinomas in the facial area bilaterally (regio facialis dextra et sinistra) in a 36-year-old patient.

rule out metastases. The patient refused surgical treatment and biopsy of the tumor formations, and did not appear for repeated follow-up examinations. She is a typical representative of the group of patients refusing surgical treatment in operable formations. This type of patient should be directed to the alternative treatments discussed in the discussion in order to limit the progression of the tumor formation and reduce their morbid risk.

\section{Discussion}

Keratinocytic cancer, including the nosological units basal cell carcinoma (BCC) and squamous cell carcinoma (SCC), is the most common cancer in patients with fair skin type [4]. Despite their high prevalence, recent studies have shown an increase in recent decades, both in terms of lifestyle and increased life expectancy [5]. The main risk factor for BCC is solar radiation, but it is worth noting some genetic phenotypes that accumulate the percentage risk of its development as dysfunction in the hedgehog signaling pathway, in p53 protein, xeroderma pigmentosum and basal cell nevus syndrome [6,7]. Although there are much evidences of low mortality in patients, we focus on the fact that a history of nonmelanoma carcinoma is associated with increased morbidity, especially with regard to advanced forms of SCC [8].

Clinically, keratinocytic cancer is presented as a solitary, growing-sized lesion of a destructive nature [9]. Morphologically, they may be scaly or smooth, skin-colored or pigmented, with or without pain symptoms, intact or ulcerated [9]. Neglecting them by both the patient and medical professionals leads to their growth and metastasis, as SCC is characterized by a higher degree of possible metastatic spread [10]. The main place in the clinical examination is occupied by the description of the morphology of the tumor formation, the dermatoscopy and the confirmation of the diagnosis by histological examination after biopsy $[11,12]$.

A specific form of keratinocytic cancer is the so called metatypical basal cell carcinoma, combining clinical and histological features of BCC and SCC [13]. There is a hypothesis that the main place in its etiology is occupied by the incorrect and unjustified use of radiation therapy as a treatment method [14]. Clinically, it is indistinguishable from BCC, and histological examination is used in the differential diagnostic plan [15].
The reason for the interest in it is its increased aggressiveness compared to typical keratinocytic cancers, expressed in the increased frequency of local recurrences and distant metastases [16]. This is why metatypical BCC should always be considered as a diagnosis by both dermatologists and general practitioners [17]. Due to the key role of radiation in its development, surgical treatment is indicated as the main in terms of therapy [17].

Other cumulative risk factors that are also significant for the development of keratinocytic cancer is immune suppression most often drug-induced in patients with chronic autoimmune diseases, or with postoperative organ transplantation [18]. The role of smoking as a proven carcinogen should not be overlooked, as there is evidence that it increases the risk of developing SCC [19].

The main place in the treatment of keratinocytic cancer is the surgical method, the elliptical excision, indicated as the most common in clinical practice [20]. It is extremely important to strictly adhere to the fields of surgical safety [20]. For BCC, the majority of authors recommend 4 millimeters from the boundaries of the tumor formation, and according to Wolf \& Zitelli complete excision is achieved in $98 \%$ of their patients with small $(<2 \mathrm{~cm})$, nodular and well demarcated formation [21]. These borders are supported by many other authors, and some of them also recommend dermatoscopic verification intraoperatively $[22,23]$. According to recent studies, the incision is incomplete in lesions larger than $2 \mathrm{~cm}$, which are more prone to subclinical invasions, and in large $(>2 \mathrm{~cm})$ and high-risk formations, fields of surgical safety between 5 and 10 millimeters are recommended $[21,24]$. The incidence of incomplete excision of $\mathrm{BCC}$ ranges between $1.54 \%$ and $28.5 \%$, and it is more common in lateral resection lines (66.19\%) compared to deep resection lines $(21.08 \%)[25,26]$. Lateral and deep resection lines were positive simultaneously in $9.89 \%$ of those treated surgically in the study $[25,26]$.

In contrast to BCC, in SCC, which has a higher invasive and metastatic potential, the fields of surgical safety are of different values [27]. In small $(<2 \mathrm{~cm})$, well-demarcated lesions, 4 millimeters from the boundaries of the formation guarantee complete excision in $95 \%$ of cases [27]. Some authors recommend 4 to 6 millimeter resection lines in this group of patients [28]. 
In tumor formations larger than $6 \mathrm{~mm}$ in high-risk areas (scalp, especially occipital, ears, nose, lips, periocular, and a history of chronic ulceration) and in tumor formations larger than $10 \mathrm{~mm}$ in medium-risk areas (other exposed parts of the body) resection lines between 6 and 10 millimeters from the boundaries of the tumor formation are recommended [28-30].

Superficial (in situ) forms can also be treated by superficial surgical techniques such as curettage, cauterization or cryotherapy, as well as by topical application of 5-fluorouracil or imiquimod containing cream [23]. When the tumor formation is in hard-to-reach places or in the middle topographic part of the face, Mohs micrographic surgery is recommended as a gold standard [24]. Radiation therapy is not recommended as a treatment for BCC, as solar radiation is among the risk factors for the development and metastasis of some forms such as metatypical BCC [17].

\section{References}

1. Thapa R, Gurung P, Hirachand S, Shrestha S. Histomorphologic Profile of Skin Tumors. JNMA J Nepal Med Assoc. 2018;56(214):953-957.

2. Gallagher R, Hill G, Bajdik C. Sunlight Exposure, Pigmentary Factors, and Risk of Nonmelanocytic Skin Cancer. Arch Dermatol. 1995;131(2):157-163.

3. Barton V, Armeson K, Hampras S, Ferris L, Visvanathan K, Rollison $D$, et al. Nonmelanoma skin cancer and risk of all-cause and cancer-related mortality:a systematic review. Arch Dermatol Res. 2017;309(4):243-251. doi: 10.1007/s00403-017-1724-5.

4. Perera E, Gnaneswaran N, Staines C, Win AK, Sinclair R. Incidence and prevalence of non-melanoma skin cancer in Australia:A systematic review. Australas J Dermatol. 2015;56(4):258-267. doi: 10.1111/ ajd.12282.

5. Armstrong B, Kricker A. The epidemiology of UV induced skin cancer J Photochem Photobiol B. 2001;63(1-3):8-18. doi: 10.1016/s10111344(01)00198-1.

6. Chiang A, Tan CZ, Kuonen F, Hodgkinson LM, Chiang F, Cho R, et al. Genetic Mutations Underlying Phenotypic Plasticity in Basosquamous Carcinoma. J Invest Dermatol. 2019 Nov;139(11):2263-2271. doi: 10.1016/j.jid.2019.03.1163.

7. Giglia-Mari G, Sarasin A. TP53 mutations in human skin cancers. Hum Mutat. 2003;21(3):217-228. doi: 10.1002/humu.10179.

8. Kallini J, Hamed N, Khachemoune A. Squamous cell carcinoma of the skin: epidemiology, classification, management, and novel trends. Int J Dermatol. 2015;54(2):130-140. doi: 10.1111/ijd.12553.

9. Lomas A, Bee J, Hextall F. A systematic review of worldwide incidence of nonmelanoma skin cancer. Br J Dermatol. 2012;166(5):1069-1080. doi: 10.1111/j.1365-2133.2012.10830.x.

10. Skulsky S, O'Sullivan B, McArdle O, Leader M, Roche M, Conlon P, et al. Review of high-risk features of cutaneous squamous cell carcinoma and discrepancies between the American Joint Committee on Cancer and NCCN Clinical Practice Guidelines in Oncology. Head Neck. 2017;39(3):578-594. doi: 10.1002/hed.24580.
11. Wolner Z, Yélamos O, Liopyris K, Rogers T, Marchetti M, Marghoob A. Enhancing Skin Cancer Diagnosis with Dermoscopy. Dermatol Clin. 2017;35(4):417-437. doi: 10.1016/j.det.2017.06.003.

12. Snow S, Sahl W, Lo S, Mohs E, Warner T, Dekkinga A, et al. Metastatic basal cell carcinoma. Report of five cases. Cancer. 1994;73(2):328335. doi: 10.1002/1097-0142(19940115)73:2<328::aidcncr2820730216>3.0.co;2-u.

13. McGregor S, Minni J, Herold D. Superficial Radiation Therapy for the Treatment of Nonmelanoma Skin Cancers. J Clin Aesthet Dermatol. 2015;8(12):12-14.

14. Tarallo M, Cigna E, Frati R, Delfino S, Innocenzi D, Fama U, et al. Metatypical basal cell carcinoma:a clinical review. J Exp Clin Cancer Res. 2008;27(1):65. doi: 10.1186/1756-9966-27-65.

15. Domarus H, Stevens J. Metastatic basal cell carcinoma. Report of five cases and review of 170 cases in the literature. J Am Acad Dermatol. 1984;10(6):1043-1060. doi: 10.1016/s0190-9622(84)80334-5.

16. Tchernev G, Ananiev J, Cardoso J, Wollina U. Metatypical Basal Cell Carcinomas:a Successful Surgical Approach to Two Cases with Different Tumor Locations. Maedica (Buchar) 2014;9(1):79-82.

17. Nagarajan P, Asgari M, Green A, Guhan S, Arron S, Proby C, et al. Keratinocyte Carcinomas: Current Concepts and Future Research Priorities. Clin Cancer Res. 2019;25(8):2379-2391. doi: 10.1158/1078-0432.CCR-18-1122.

18. Nadhan K, Chung C, Buchanan E, Shaver C, Shipman S, Allawh $\mathrm{R}$, et al. Risk factors for keratinocyte carcinoma skin cancer in nonwhite individuals: A retrospective analysis. J Am Acad Dermatol. 2019;81(2):373-378. doi: 10.1016/j.jaad.2019.01.038.

19. Temelkova I, Mangarov H, Tronnier M, Terziev I, Tchernev G. Eruptive Basaliomas: "Why we have to Perform Surgery?" Or Said Otherwise: “Catch The Metatypical!”. Open Access Maced J Med Sci. 2018;6(8):1435-1437. doi: 10.3889/oamjms.2018.203.

20. Wolf DJ, Zitelli JA. Surgical Margins for basal cell carcinoma. Arch Dermatol. 1987;123:340-344.

21. Kimyai-Asadi A, Alam M, Goldberg LH, Peterson SR, Silapunt S, Jih $\mathrm{MH}$. Efficacy of narrow-margin excision of well-demarcated primary facial basal cell carcinoma. J Am Acad Dermatol. 2005;53:464-468. doi: 10.1016/j.jaad.2005.03.038.

22. Thomas DJ, King AR, Peat BG. Excision margins for nonmelanotic skin cancer. Plast Reconstr Surg. 2003;112:57-63. doi: 10.1097/01. PRS.0000067479.77859.31.

23. Pichardo-Velázquez P, Domínguez-Cherit J, Vega-Memije Ma, Moreno-Coutiño G, Proy H. Surgical option for nonmelanoma skin cancer. Int J Dermatol. 2004;43:148-150. Doi: 10.1111/j.13654632.2004.02091.x.

24. Kumar P, Watson S, Brain AN, Davenport PJ, McWilliam LJ, Banerjee $\mathrm{SS}$, et al. Incomplete excision of basal cell carcinoma: a prospective multicentre audit. Br J Plast Surg. 2002;55(8):616-622. doi: 10.1054/ bjps.2002.3948.

25. Hakverdi S, Balci DD, Dogramaci CA, Toprak S, Yaldiz M. Retrospective analysis of basal cell carcinoma. Indian J Dermatol Venereol Leprol. 2011;77(2):251. doi: 10.4103/0378-6323.77483.

26. Brodland D, Zitelli JA. Surgical margins for excision of primary cutaneous squamous cell carcinoma. J Am Acad Dermatol. 
1992;27:241-248. doi: 10.1016/0190-9622(92)70178-i.

27. Mohs F, Snow SN. Microscopically controlled surgical treatment for squamous cell carcinoma of the lower lip. Surg Gynecol Obstet. 1985;160(1):37-41.

28. Mohs FE. Chemosurgical treatment of cancer of the ear: a microscopically controlled method of excision. Surgery. 1947;21(5):605-622.
29. Cullen J, Simmons J, Parsons P, Boyle G. Topical treatments for skin cancer. Adv Drug Deliv Rev. 2019. doi: 10.1016/j.addr.2019.11.002.

30. Jiménez Y, Camarero-Mulas C, Sanmartín-Jiménez O, Garcés J, Rodríguez-Prieto M, Alonso-Alonso T, et al. Differences of Mohs micrographic surgery in basal cell carcinoma versus squamous cell carcinoma. Int J Dermatol. 2018;57(11):1375-1381. doi: 10.1111/ ijd.14223. 